\section{Measurement of the Hardness and Indentation Modulus of Sands treated with Enzyme Induced Carbonate Precipitation}

\author{
VINAY KRISHNAN, FARIDEH EHSASI, MARYAM \\ KAZEMBEYKI, LEON VANPAASSEN, CHRISTIAN \\ HOOVER, HAMED KHODADADI TIRKOLAEI AND \\ EDWARD KAVAZANJIAN JR.
}

Arizona State University

Presenting Author: vkrishnan@asu.edu

The indentation hardness and modulus of calcium carbonate precipitated at contacts between sand grains via enzyme induced carbonate precipitation (EICP) were evaluated using micro- and nano-indentation. EICP is based on the enzymatically catalyzed hydrolysis of urea, which in presence of dissolved calcium ions induces the precipitation of calcium carbonate minerals and has potential applications as a ground improvement method. When EICP is applied in granular soils the carbonate minerals fill up the pore space and cement the grains, increasing soil strength and stiffness. It has been demonstrated that the addition of nonfat dry milk improves the strength of the bio-cemented quarzitic sands at similar calcium carbonate content. One of the possible explanations for the observed phenomena is that the organic polymers in the milk affect the properties of the calcium carbonate minerals or the bond strength between the precipitates and the host grains. To test this hypothesis, columns of a standard quarzitic sand (Ottawa 20-30) were bio-cemented using a baseline and a modified EICP solution (modified with nonfat dry milk). Following EICP treatment, specimens of biocemented sand were retrieved from the columns and subjected to XRDanalysis and indentation testing. X-ray diffractograms of the biocemented sands showed that the predominant mineral precipitated in the baseline EICP treatment as well as the modified EICP treatment was calcite. Current micro-indentation results show that the hardness and indentation modulus conform the values for quartz and calcite expected from literature. It is anticipated that the precipitate in specimens treated with the modified EICP solution has a different hardness and indentation modulus compared to the precipitate in specimens treated with the baseline EICP solution, particularly at the interface.

Figure 1. Load-displacement plot and indentation footprint during nanoindentation (representative, not on a specimen of EICP-treated sand).

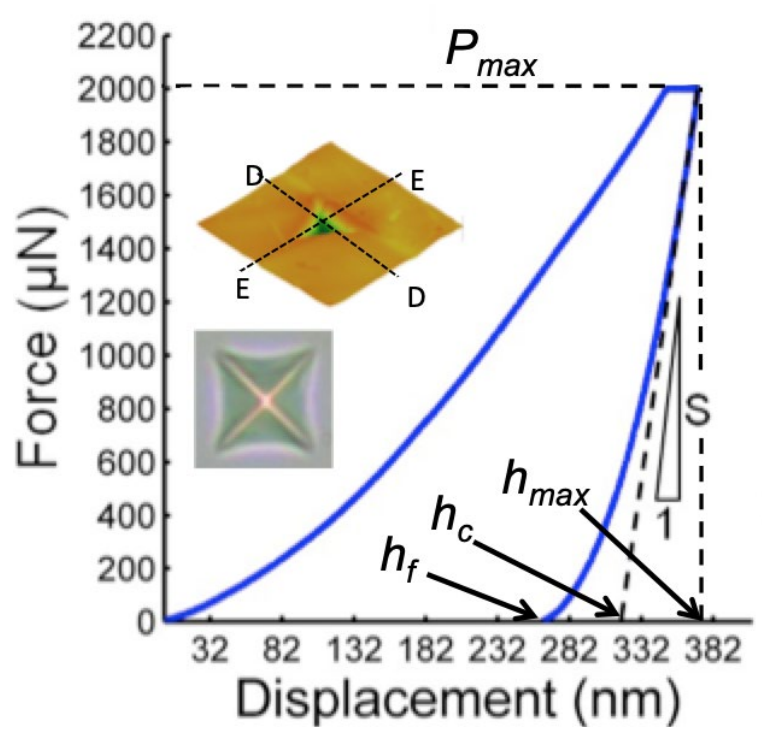

